CASE REPORT

\title{
Prolonged QT interval in an infant of a fluoxetine treated mother
}

\author{
G Dubnov, R Fogelman, P Merlob
}

Arch Dis Child 2005;90:972-973. doi: 10.1136/adc.2004.064618

Fluoxetine is an antidepressant drug, only recently discovered to be a QT interval prolonging agent. The first case is presented of an infant of a mother treated with fluoxetine during pregnancy who had a transiently prolonged QTC interval, concluded to be drug induced. Clinical and electrocardiographic monitoring of newborns of antidepressant treated mothers is needed.

$\mathrm{F}$ luoxetine is a selective serotonin reuptake inhibitor (SSRI) commonly used for the treatment of depression. SSRIs have been found to be superior to the traditional tricyclic antidepressants because of their lower profile of adverse effects. These findings may extend also to newborns of treated mothers. ${ }^{1}$ Fluoxetine was originally considered to have no electrocardiographic effects. Several recent publications, however, have associated fluoxetine with QT prolongation. $^{2-5}$ We describe the first case of a newborn of a mother treated with fluoxetine throughout pregnancy with a prolonged corrected QT interval (QTC) on the initial routine electrocardiogram (ECG).

\section{CASE REPORT}

A male infant was born after 40 weeks' gestation to a 41 year old mother, gravida 3, para 1, abortus 2 (one spontaneous, one induced), who had been treated throughout pregnancy with fluoxetine, $30 \mathrm{mg}$ daily, for depression, and Eltroxin for hypothyroidism. The pregnancy was uncomplicated, with normal triple test, amniocentesis, and fetal ultrasound results. Birth was vacuum assisted, Apgar score was normal. Umbilical cord blood gas levels were within normal range.

Birth weight was $2975 \mathrm{~g}$, length $50 \mathrm{~cm}$, head circumference $34.5 \mathrm{~cm}$-all appropriate for gestational age. Physical examination revealed a well appearing infant; a mild $1 / 6$ systolic murmur at the lower left sternal border was the only clinical finding. The infant was placed in a clear incubator with a cardiorespiratory monitor to screen for SSRI withdrawal symptoms using the Finnegan Neonatal Abstinence Scoring System. Blood tests were performed in accordance with our departmental protocol for all infants born to SSRI treated mothers. Blood chemistry values at age 24 hours were within normal range: sodium $141 \mathrm{mEq} / \mathrm{l}$, potassium $5.7 \mathrm{mEq} / \mathrm{l}$, chloride $108 \mathrm{mEq} / \mathrm{l}$, creatinine $1.0 \mathrm{mg} / \mathrm{dl}$, urea $32 \mathrm{mg} / \mathrm{dl}$, calcium $9.7 \mathrm{mg} / \mathrm{dl}$, phosphorus $6.2 \mathrm{mg} / \mathrm{dl}$. Liver enzyme levels, coagulation function tests, and a complete blood count were normal. A routine electrocardiogram (ECG) was performed at around 30 hours of age (fig 1). Analysis revealed a QRS rate of 120 and sinus rhythm, axis of 110 degrees, and normal P wave, QRS complex, and ST segment morphology. PR interval was 0.08 seconds, QRS duration was 0.06 seconds, and QTc interval, as determined by Bazett's formula, was 0.54-0.58 seconds. An echocardiogram was completely normal. The ECG was repeated on the following days and showed a decline in interval to $0.38-0.36$ seconds.

The hospitalisation course was uneventful. At the age of 2 months, a repeated ECG performed by the child's physician was reported to have a QTC of 0.42 seconds. On follow up at age 4 months, the infant's mother reported normal growth and development.

\section{DISCUSSION}

The normal QTc interval in newborns is $0.44-0.47$ seconds. ${ }^{6} 7$ In one study conducted among 4200 infants, only two infants had a QTc interval longer than 0.5 seconds at the age of 4 days. ${ }^{8}$ The longest QTc interval was 0.563 , and that infant had died a sudden infant death. Prolongation of the interval by more than $30 \%$ of baseline or a duration of 0.06 seconds or more predisposes the infant to torsades des pointes, a potentially fatal arrhythmia. ${ }^{3}$ In the case presented, the QTC interval on the first ECG was $0.54-0.58$ seconds, which was prolonged by $42-61 \%$, compared with subsequent tracings.

There are several reasons for QTc prolongation in a neonate: familial long QT syndrome (LQTS), hypoxia, and electrolyte disturbances brought about by various mechanisms. Our patient was well appearing, and first underwent ECG after 30 hours on a cardiorespiratory monitor, ruling out the presence of ongoing hypoxia. On laboratory workup, plasma electrolyte levels were within normal range. Although hypothyroidism may also prolong the QT interval, the Eltroxin treated mother had normal thyroid stimulating hormone levels around the time of pregnancy and birth, and neonatal thyroxine screening results were normal. Regarding LQTS, the mother stated no knowledge of sudden death in her family, and her ECG performed during pregnancy was normal. The mother was a single parent, and paternal data were unavailable. These findings, along with the transient nature of the QTc prolongation, reduced the probability of LQTS. The maternal use of fluoxetine, a drug reported to cause QTc prolongation in users, remained the most likely cause of the QTc prolongation in the infant.

Fluoxetine is not contraindicated in pregnancy. ${ }^{9}{ }^{10}$ In a recent study of the effects of maternal SSRI use on newborns,

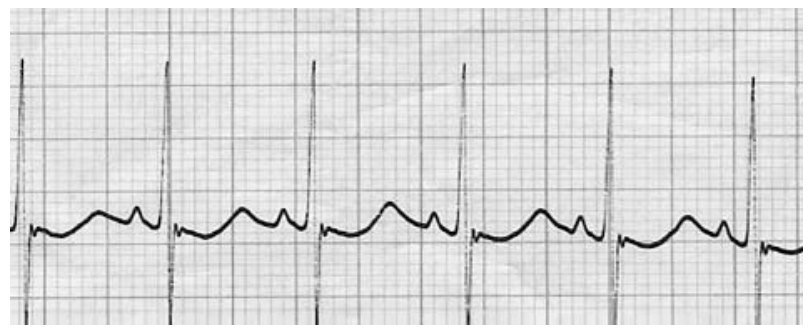

Figure 1 ECG performed at 30 hours of age showing QTc prolongation, as calculated by Bazett's formula. 
higher rates of preterm delivery, low birth weight, respiratory distress, low Apgar score, and convulsions were noted. ${ }^{1}$ Although early studies, conducted on a small number of patients, did not report alterations in the QTc interval, ${ }^{11-13}$ fluoxetine is now considered a QTc prolonging drug. ${ }^{2-5}$ One possible mechanism is blockage of the same cardiac potassium channels which, when mutated, cause some cases of LQTS. ${ }^{14}$

Proper measurement of the QTC interval in infants is a challenging task. One study of 53 ECG recordings from neonates showed large inter-observer and intra-observer differences. ${ }^{15}$ Therefore, in our case, T-wave measurements were conducted in several beats, and the interpretation was confirmed by a paediatric cardiologist.

In conclusion, we describe an infant born to a fluoxetine treated mother whose initial ECG recording revealed a prolonged QTc interval. Studies associating fluoxetine with QTc prolongation in users, together with our findings of an absence of electrolyte disturbances and a very low probability of LQTS, suggest that the prolonged QTc interval in this case was drug related. Therefore, in addition to clinical monitoring for SSRI discontinuation syndrome, we recommend that infants of fluoxetine treated mothers undergo cardiac electrical activity monitoring and routine ECGs.

\section{Authors' affiliations}

G Dubnov, P Merlob, Department of Neonatology, Rabin Medical Center, Beilinson Campus, Petah Tiqva, Sackler Faculty of Medicine, Tel Aviv University, Tel Aviv, Israel

R Fogelman, Department of Pediatric Cardiology, Schneider Children's Medical Center of Israel, Petah Tiqva, Sackler Faculty of Medicine, Tel Aviv University, Tel Aviv, Israel

Competing interests: none
Correspondence to: Dr G Dubnov, Department of Neonatology, Rabin Medical Center, Beilinson Campus, Petah Tiqva 49202, Israel; gald@ clalit.org.il

Accepted 30 March 2005

\section{REFERENCES}

1 Kallen B. Neonate characteristics after maternal use of antidepressants in late pregnancy. Arch Pediatr Adolesc Med 2004; 158:312-16.

2 Varriale P. Fluoxetine (Prozac) as a cause of QT prolongation. Arch Intern Med 2001;161:612.

3 Yap YG, Camm AJ. Drug-induced QT prolongation and torsades de pointes. Heart 2003;89:1363-72.

4 Curtis LH, Ostbye T, Sendersky V, et al. Prescription of QT-prolonging drugs in a cohort of about 5 million outpatients. Am J Med 2003;1 14:135-41.

5 Viskin S, Justo D, Halkin A, et al. Long QT syndrome caused by noncardiac drugs. Prog Cardiovasc Dis 2003;45:415-27.

6 Garson A. Electrocardiography. In: Garson A, Bricker JT, Fisher DJ, Neish SR, eds. The science and practice of pediatric cardiology, 2nd edn. Baltimore, MD: Williams and Wilkins, 1998

7 Flanagan MF, Yeager SB, Weindling SN. Cardiac disease. In: Avery GB Fletcher MA, MacDonald MG, eds. Neonatology: pathophysiology and management of the newborn. Philadelphia, PA: Lippincott Williams and Wilkins, 1999.

8 Schwartz PJ, Montemerlo M, Facchini M, et al. The QT interval throughout the first 6 months of life: a prospective study. Circulation 1982;66:496-501.

9 Briggs GG, Freeman RK, Yaffe SJ. Drugs in pregnancy and lactation. Philadelphia, PA: Lippincott Williams and Wilkins, 2002.

10 Friedman JM, Polifka JE. The effects of neurologic and psychiatric drugs in the fetus and nursing infant. Baltimore and London: Johns Hopkins University Press, 1998.

11 Fisch C. Effect of fluoxetine on the electrocardiogram. J Clin Psychiatry 1985;46:42-4

12 Upward JW, Edwards JG, Goldie A, et al. Comparative effects of fluoxetine and amitriptyline on cardiac function. Br J Clin Pharmacol 1988;26:399-402.

13 Roose SP, Glassman AH, Attia E, et al. Cardiovascular effects of fluoxetine in depressed patients with heart disease. Am J Psychiatry 1998;155:660-5.

14 Thomas D, Gut B, Wendt-Nordahl G, et al. The antidepressant drug fluoxetine is an inhibitor of human ether-a-go-go-related gene (HERG) potassium channels. J Pharmacol Exp Ther 2002;300:543-8.

15 De Groote K, Suys B, Deleeck A, et al. How accurately can QT interval be measured in newborn infants? Eur J Pediatr 2003;162:875-9. 